\title{
Japanese media scent Nobels in superconductor race
}

\section{Kyoto}

HiGH-temperature superconductivity still has the power to switch on the media (if nothing else). The 18th International Conference on Low Temperature Physics opened in Kyoto last week under the full glare of television cameras and lights. And on the second day a Japanese researcher set the cameras rolling again with a claim of superconductivity at $338 \mathrm{~K}\left(65^{\circ} \mathrm{C}\right)$ in a new type of copper oxide.

The conference, sponsored by the International Union of Pure and Applied Physics, the Science Council of Japan, the Physical Society of Japan and the Japan Society of Applied Physics, has been swamped by contributions on high- $T_{\text {. }}$ superconductors, with over 200 of the 1,000 -odd presentations (talks and posters) in the field. And nearly half (41 per cent) of the $¥ 120$ million $(\$ 800,000$ million) cost of the six-day conference has been put up by Japanese industries interested in the development of the new superconducting materials.

At the opening ceremony on 20 August, 20 recipients of the Fritz London Memorial Award found themselves at the centre of attention befitting Nobel Prize winners. John Clarke from the University of California won recognition for his pioneering development of SQUIDS (superconducting quantum interference devices) and SLUGS (superconducting low-inductance galvanometers), work he began at the Cavendish Laboratory of the University of Cambridge in the 1960s. And Jun Kondo of Japan's Electrotechnical Laboratory was given an award for his explanation of the resistance minimum in metallic systems with magnetic impurities. But the television cameras and floodlights were for J.G. Bednorz and K.A. Müller, who shared the third award for their discovery, last year, of superconductivity in $\mathrm{Ba}-\mathrm{La}-\mathrm{Cu}$ oxides.

The television crews got another shot at the stars of high- $T_{c}$ superconductivity on the following day when five of the world's leading researchers presented review papers. Although nothing particularly startling was said, the photographers rushed forward en masse at the start of each talk for their allotted one minute of picture-taking.

V.L. Ginzburg of the Academy of Sciences of the USSR, who was given an unscheduled slot at the end of the review session, waved the press aside, pointing out that he could not possibly say much of significance in three minutes. He then chided his colleagues for being swept away in the "mania" of high-temperature superconductivity (although he noted it had provided him with his first opportunity in 44 years of research to attend the low-temperature physics conference) and he appealed to young researchers to avoid "unhealthy conflict".

But at the afternoon poster session on high- $T_{\mathrm{c}}$ superconductors, the mania continued, with packed aisles more reminiscent of a Tokyo station during rush hour than a scientific conference. And the television crews continued to trail the review speakers, asking questions like "Do you think you will get a Nobel Prize?".

Dr H. Ihara of the Ministry of International Trade and Industry's Electrotechnical Laboratory grabbed the most limelight, however, when he announced during Friday evening's short-talk session that he had observed zero resistance in the new $\mathrm{Y}-\mathrm{Sr}-\mathrm{Ba}-\mathrm{Cu}$ oxide $\left(\mathrm{YSrBaCu} \mathrm{O}_{8-\delta}\right.$,

$\delta>0.2$ ) at $338 \mathrm{~K}$. Flash bulbs lit up the hall when Ihara presented a resistancetemperature curve that plunged to zero $\left(10^{-8} \Omega_{\mathrm{cm}^{-2}}\right)$ above room temperature and again when he showed a curve of magnetic susceptibility with a slight break in slope at almost the same temperature ( $340 \mathrm{~K})$.

But audience reaction was sceptical. Zero resistance, although stable for ten days in one of the two samples (one day in the other), was observed in only about 0.01 per cent of the 9-mm-diameter sample in a zone confined to the perimeter of the disk. Some suspect that the isolated observations of zero resistance could be an artefact of minute cracks in the sample that open and close due to thermal expansion and contraction.

Yet, despite the scepticism, the telephone lines in Kyoto were set abuzz that night, not only by the press but also by researchers calling home to their laboratories with the recipe for the latest oxide.

David Swinbanks

\section{Japan's education reformers rallying round the flag}

Tokyo

JAPAN's National Council on Education Reform has ended its three years of deliberations without finding a clear solution to the education system's biggest problem of intense competition for places in elite universities. It does propose some university reforms, principally that the universities should change the start of their academic year from April to September to fall in line with other countries, and that the research system should be altered. But no date is given for the former change and the latter is left largely to a yet unformed university council.

The council's final report criticizes the education system for its failure to encourage individuality and bring forth scholars of international standing. But the deep division over how to tackle these problems reflects the conflicting views of traditionalists, aligned with the Ministry of Education, Culture and Science, and those seeking radical reform. The report stresses, on the one hand, the need to foster children with liberal and autonomous minds who can develop their creativity and, on the other, the inculcation of patriotism and respect for social norms.

Overall it would seem that the traditionalists have gained the upper hand. Since the council brought out earlier versions of these proposals, the Ministry of Education, Culture and Science has moved to encourage schools to display the national flag and enforce singing of the national anthem. Some school districts have fallen into line. Elsewhere there have been protests, especially from those who remember pre-war nationalist days.
In Okinawa, an irate mother ripped down the flag at her child's school entrance ceremony to a mixture of applause and boos from the audience.

The intense competition for entry to top universities which forces children to spend long hours at evening cramming schools seemed beyond the council's ability to tackle. Change is likely to come only if government ministries and large companies stop giving preference to graduates of elite universities. All the council could do was to call for local education boards to "look into" cram schools and "to try to solve problems, if there are any". Support is given to the idea of life-long education and the council chairman, Professor Michio Okamoto, hopes that improved educational opportunities for working adults might do something to ease the competition for university entrance. So far, however, university faculties that run public lecture courses have often run into opposition from colleagues who are competing for scarce resources.

In the universities, a call is made for shorter-term appointments to replace the lifetime employment system. Encouragement is also given to a review of the grant system, the increase of funds for research, and an improvement of the postdoctoral fellowship system. At present, only a few hundred postdoctoral fellowships are available. Despite over 2,000 hours of debate by the council, many of the universities' key problems, such as the chronic lack of technicians, were left unresolved. A new "university council" is planned to take over where the reform council left off.
David Swinbanks 